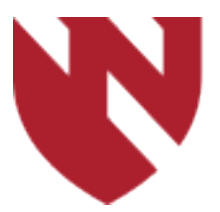

December 2019

\title{
Morbidity and Mortality Conference: Cultivating a Culture of Safety
}

Kaitlin Hahn

University of Nebraska Medical Center

Jeffrey Harrison

University of Nebraska Medical Center

Tell us how you used this information in this short survey.

Follow this and additional works at: https://digitalcommons.unmc.edu/gmerj

Part of the Higher Education Commons, and the Medicine and Health Sciences Commons

\section{Recommended Citation}

Hahn, K., , Harrison, J. Morbidity and Mortality Conference: Cultivating a Culture of Safety. Graduate Medical Education Research Journal. 2019 Dec 13; 1(1).

https://digitalcommons.unmc.edu/gmerj/vol1/iss1/63

This Conference Proceeding is brought to you for free and open access by DigitalCommons@UNMC. It has been accepted for inclusion in Graduate Medical Education Research Journal by an authorized editor of DigitalCommons@UNMC.For more information, please contact digitalcommons@unmc.edu. 


\section{Morbidity and Mortality Conference: Cultivating a Culture of Safety}

Creative Commons License

(c) 1 (1) (9)

This work is licensed under a Creative Commons Attribution-Noncommercial-No Derivative Works 4.0 License. 


\section{Improvement in Quality Metrics using Clinical Decision Support: Incorporating the Process in the Military Practice}

Faraz Ghoddusi, Tanvir Hussein, Michael Ash

Mentor: Tanvir Hussein

Program: Family Medicine

As a part of the Medicare Quality Payment Program: (QPP), reimbursement now depends on pay-for-performance quality measures, with the percentage of Medicare payments - incentives and penalties - being dependent on performance, and increasing in size annually. The intent of this project was to expand the learning of quality metrics within the academic setting into the systemic approach found in the Department of Defense.
Here at UNMC, we designed and implemented clinical decision support, called Quality Metric Alerts, and an electronic health record (EHR)-integrated provider quality dashboard for twelve significant Patient Quality Reporting System (PQRS) measures. We implemented the metric alerts quarterly, three at a time, and found improvement in all measured metrics that continued with each successive wave of implementation. The greatest improvement was seen in process measures allowing the entire clinic team to participate in care delivery, which is consistent with the patient centered healthcare model of the military health system. We also found that performance did not deteriorate as additional metrics were implemented, thus refining quality improvement projects within Ehrling Bergquist Clinic (the Offutt AFB Medical Treatment Facility), and allowing us to utilize our limited resources with an optimized strategy.

https://doi.org/10.32873/unmc.dc.gmerj.1.1.062

\section{Morbidity and Mortality Conference: Cultivating a Culture of Safety Kaitlin Hahn, Jeffrey Harrison}

Mentor: Jeffrey Harrison

Program: Family Medicine

Background and Objectives: Medical errors are the third leading cause of death in the United States - contributing to 700 deaths per day. Morbidity and Mortality Conference serves as a venue for residents to identify areas of improvement, display transparency in patient care, promote leadership, and develop quality improvement skills. The University of Nebraska Department of Family Medicine was lacking a formal Morbidity and Mortality Conference. The main objective of this educational project was to implement a quality improvement platform while cultivating a standard of safety and incorporating the six ACGME core competencies.
Methods: Baseline knowledge was assessed with a pre-conference survey. An overview of expected conference format, ACGME competencies, and case selection process were reviewed. Quarterly time was allotted. Following each presentation, residents completed a post-conference survey. Presenters were responsible for implementation of suggested quality improvement measures.

Results: Four cases representing inpatient, ambulatory, and obstetric medicine were presented. Surveys demonstrated improvement in resident abilities to perform root cause analysis while maintaining a non-punitive environment. Each case resulted in multiple patient safety and quality improvement actions and all core competencies were represented.

\section{Papillary Thyroid Carcinoma within a Thyroglossal Duct Cyst \\ Madeline L Jones-Ryan and Whitney Goldner}

Mentor: Whitney Goldner

Program: Diabetes, Endocrinology, and Metabolism

Introduction: A thyroglossal duct cyst is a developmental anomaly caused by the failure of the thyroglossal duct to atrophy during development. This is present in about $7 \%$ of the population. Carcinoma in a thyroglossal duct cyst is present in about $1 \%$ of this population. The majority of those carcinomas are papillary thyroid carcinoma.

Case Description: A young adult patient presented to the PCP with the complaint of a new palpable midline neck mass that the patient noted when resting his/her chin on hands. Ultrasound and CT of the neck showed a heterogenous ill-defined mass that abutted the hyoid bone. At that time, the patient was sent to an otolaryngologist who performed an FNA that showed atypical cells. The patient underwent excision of the thyroglossal duct cyst via the Sistrunk Procedure. The pathologic evaluation showed a thyroglossal duct cyst and a $3.1 \mathrm{~cm}$ papillary thyroid carcinoma. The patient then underwent a total thyroidectomy, which revealed a co-existing papillary thyroid microcarcinoma $(3 \mathrm{~mm})$. The patient then underwent radioactive iodine treatment.

Discussion: Papillary thyroid carcinoma in a thyroglossal duct cyst is an uncommon malignancy. It is important to be aware of this possibility in thyroglossal duct cysts.
Conclusions: Implementation of Morbidity and Mortality Conference within UNMC Department of Family Medicine contributes to resident education while identifying areas of quality improvement and patient safety on a system level. The intent is to continue the conference quarterly and involve all interdisciplinary team members in the case submission and presentation process. Continued research is needed to determine objective measures of implementation of patient safety improvement actions within UNMC.

https://doi.org/10.32873/unmc.dc.gmerj.1.1.063

Surgical removal is recommended for definitive diagnosis and treatment of the thyroglossal duct cyst. When papillary thyroid carcinoma is preset, then definitive treatment includes total thyroidectomy and radioactive iodine given the risk of cervical lymph node metastasis.

https://doi.org/10.32873/unmc.dc.gmerj.1.1.064 